\title{
REFLEKSI TERHADAP UNDANGAN ALLAH KE DALAM PERJAMUAN BESAR DAN TIPIKAL RESPONS MANUSIA (Lukas 14:15-24)
}

\author{
Hadi P. Sahardjo
}

\begin{abstract}
Through this parable, we can learn about God's plan about men. His invitation couldn't be rejected. God's grace is still abundantly poured on us. But if someone reject it, he/she must give the responsibility to God. The parable symbolizes and represents: the salvation offered to the Jews and their rejection of the Saviour (the first call); indicate the Gentile sinners and harlots who warmly welcomed the Son of God and pressed eagerly into His Kingdom (the second call); and the third call represents the wanderers of outlying Gentile world, the world's "broken earthenware," upon whom moral compulsion has to be used.

God's grace always widely opened to everyone, it depend on how we respond on it. We are sure that this parable point to the Kingdom of God and His saving plan upon men and how must we respond it. Likewise if God calls men, no one can reject it. If they reject it, they will face the punishments of God. "Not one of those men who were invited (but rejected the invitation) will get a taste of my banquet" (Luk. 14:24). And "The Son of Man came to seek and to save what was lost" (Luk. 19:10).
\end{abstract}

\section{PENDAHULUAN}

Untuk memahami sebuah perumpamaan, memang tidak terlalu mudah, kecuali sudah dikatakan sendiri oleh Tuhan Yesus akan arti 
perumpamaan tersebut. Misal;nya perumpaan tentang penabur benih. Jelas sekali apa yang dimaksud, karena langsung dijelaskan maknanya oleh Tuhan Yesus sendiri (Mat. 13:1-23). Di lain pihak, kita juga harus menjelaskan perumpaan itu sebagaimana adanya. Tidak boleh menafsirkan atau mengatakan apa yang tidak dikatakan oleh Alkitab dan harus dimengerti dengan konteks yang terjadi di sekitar dan pada saat itu (Sits im Leben).

\section{HISTORICAL SETTING}

Perumpamaan tentang "Perjamuan Besar" ini termasuk dalam kategori Narrative Journey. Perumpamaan yang bisa dibandingkan dengan Matius 22:1-10(14). Perumpamaan dalam Luk. 14:15-24 ini tidak lepas dari tradisi pesta (perjamuan) Palestina-Yudaisme pada abad pertama. Kebiasaan Gerika mereka makan tiga kali dalam sehari. Kalau kebiasaan makan orang-orang Romawi, malah empat kali. Tetapi Yahudi Palestina makan justru hanya dua kali. Yang pertama adalah sarapan (yang sudah agak kesiangan) pada kurang lebih jam 10.00. Yang kedua adalah makan malam, yang biasanya dilakukan setelah mereka selesai bekerja. ${ }^{1}$

Menurut kebiasaan, penyelenggaraan pesta/perjamuan itu dilaksanakan pada petang hari. Ada dua kali undangan yang disampaikan. Sebelum pesta yang sebenarnya resmi dimulai tuan yang punya hajat pesta akan menyuruh hambanya untuk memberitahukan kepada orang yang diundang tentanbg akan diadakannya pesta. Ini tercermin pada ayat 16. Sedangkan undangan yang kedua disampaikan pada saat acara pesta yang sebenarnya akan segera dimulai. ${ }^{2}$ Jadi sebenarnya cukup waktu bagi orang yang diundang agar bisa memersiapkan diri menghadiri pesta dimaksud. Ini dindikasikan pada ayat 17.

\section{KAJIAN KONTEKS}

1 Robert H. Stein. An Introductions to the Parables of Jesus. (Chicago: The Wstminster Press, 1981), 84.

${ }^{2}$ Ibid. 
Perumpamaan tentang "Perjamuan Besar" ini diucapkan oleh Tuhan Yesus di hadapan sekelompok orang di rumah seorang Parisi pada saat Tuhan Yesus diundang makan (14:1 dst.). Di samping itu pewristiwa yang terjadi di sekitar perjamuan itu juga menarik Tuhan Yesus, dimana ada beberapa tamu yang saling berebut untuk mencari tempat yang terhormat (14:7 dyb.), dan akhirnya pernyataan langsung kepada orang yang mengundang-Nya untuk makan, tentang siapa sebaiknya yang harus diundang apabila mengadakan pesta. Antara yang dicatat dalam Matius dengan Lukas meskipun kelihatannya sama, tetapi kalau dicermati seperti di atas ternyata sangat banyak perbedaannya. Namun memiliki esensi yang sama. Scott mengatakan bahwa perjamuan itu merupakan salah satu tanda atau lambang kemenangan Allah terhadap musuh-Nya. ${ }^{3}$ Herbert Lockyer menulis bahwa Perjamuan Kawin itu diucapkan oleh Tuhan Yesus masih pada awal pelayanan Tuhan kita Yesus Kristus, sedangkan Perjamuan Besar itu diadakan pada minggu sebelum Paskah. ${ }^{4}$ Kalau dalam Matius diucapkan di hadapan banyak orang di Bait Suci, sedangkan Lukas diucapkan pada saat Yesus makan di rumah salah seorang pemimpin Parisi (Luk. 14:1). Beberapa sarjana dan penafsir mengatakan bahwa tidaklah mustahil bagi Tuhan Yesus untuk memakai dalam perumpamaan ini beberapa unsur dari suatu ceita kuno orang Yahudi, yaitu cerita tentang seorang pemungut cukai yang kaya, bernama Bar Ma'yam. ${ }^{5}$ Jadi Yesus memakai suatu gambaran perjamuan yang besar untuk melukiskan keselamatan dalam Kerajaan Allah. ${ }^{6}$

\section{KAJIAN TEKS}

3 Bernard Brandon Scott. Hear Then the Parable. (Minneapolis: Fortrees Press, (1989), 169.

${ }^{4}$ Herbert Lockyer. All the Parables of the Bible. (Grand Rapids, MI.: Lamplighter Books, 1989), 275.

5 B.J. Bolland. Tafsiran Lukas. Jakarta: BPK Gunung Mulia, 1970), 316.

${ }^{6}$ Ibid. 
Darrel Bock mencoba untuk membandingkan antara kedua perumpamaan yang memiliki kemiripan ini sebagai berikut: ${ }^{7}$

\section{Elemen}

Giver of the banquet

Banquet

Structure of the first

invita- tion

Reaction to the

invitation

Host's response

Second set of invitees

Response to second set of invitations

Ending
Matthew

King

Wedding feast

Two invtations by many servants

Invitees return to field

and business with

laugher, while others beat

the servants

King sends troops to destroy invitees and invites new guests

Many

One gathering comes

Uninvited visitor without a wedding garment is removed

\section{Luke}

Master of the house

Dinner banquet

One invitation by one servant

Three excuses given, no beatings

Host invites new guests

Poor, lame, blind, and crippled

One gathering does not fill the house, so another set of invitations is given A saying abaout original invitees not being at the meal

Dari sini nampak jelas bahwa kendatipun kelihatannya sama, tetapi kalau dicermati maka akan segera nampak perbedaan yang ada, baik dari pengundang, pelayan maupun sikap dan ending pesta dalam perumpamaan tersebut. Sehingga sangat mungkin bahwa ini adalah dua peristiwa yang berbeda tetapi memiliki kemiripan. Memang ada beberapa sarjana yang mengatakan bahwa ini sebenarnya dua perumpamaan yang sama, misalnya B.J. Bolland. ${ }^{8}$ Tetapi ada juga yang mengatakan itu sebagai dua perumpamaan yang berbeda. Frederick Houk Borsch mengatakan bahwa Lukas menuliskannya secara sekuler, sehingga sangat

7 Darrell L. Bock. Luke (9:51-24:53). Baker Books House, Grand Rapiuds, MI. (1998), 1269-1270.

${ }^{8}$ B.J. Bolland. Ibid. 
sedikit menulis hal-hal yang detil berkaitan dengan alegori sejarah keselamatan. ${ }^{9}$

\section{PEMBAGIAN : SETTING NARASI}

Ayat 16-17: Undangan pertama dari tuan yang mengadakan perjamuan. Orang-orang yang diundang pastilah orang-orang pilihan. Yang dihormati, mungkin juga orang yang berkedudukan. Juga mereka yang dikenal baik oleh tuan rumah. Tuan yang mengadakan perjamuan besar itu menyuruh hamba-hambanya untuk mengundang banyak orang: "Marilah, sebab segala sesuatu sudah siap ...". Pesta ini ditujukan kepada para undangan dengan tidak mengikuti kelaziman yang berlaku pada waktu itu. ${ }^{10}$ Orang biasanya mengundang dengan perintah kepada para pelayan dengan pemberitahuan tentang waktu akan diselenggarakannya pesta, misalnya: "Besuk jam 18.00 hingga jam 20.00 tuan diundang menghadiri pesta di rumah tuan saya". Tetapi pola yang dipakai dalam perumpamaan ini berbeda sekali. Perintah itu langsung diberikan, dan harus segera dilaksanakan (14:17). Berarti tuan yang mengundang ini memiliki kuasa dan kekuatan yang lebih dibanding dengan yang diundang, sehingga undangan itu tidak bisa dibantah.

Ayat 18-20: Permintaan maaf para undangan. Ternyata mereka ini justru menolak undangan yang sudah dipersiapkan oleh tuan rumah. Tidak dijelaskan alasan utama mereka tidak datang itu, selain dalih mengapa mereka tidak bisa datang, meskipun disertai dengan permintaan maaf. Penolakan yang sengaja ini tidak memersoalkan apakah mereka tidak mau datang karena tidak suka dengan tuan yang mengadakan pesta tersebut (kalau benar misalnya dia adalah seorang pemungut cukai sehingga barangkali masyarakat tidak menyukainya). Yang penting adalah penolakan mereka itu justru terletak pada alasan-alasan yang dibuat-

9 Frederick Houk Borsch. Many Things in Parables. (Philadelphia: Fortress Press, 1989), 48.

${ }^{10}$ Ibid. 169-170. 


\section{6 | REFLEKSI PANGGILAN PERJAMUAN BESAR}

buat. Orang-orang yang pertama diundang itu berdalih bahwa mereka baru saja (1) membeli ladang, (2) membeli lembu dan (3) baru kawin. Dengan ketiga dalih itu mereka menolak undangan yang disampaikan kepada mereka, meskipun disertai permintaan maaf.

Mereka tidak mempedulikan undangan yang disampaikan kepada mereka. Kelihatannya alasan mereka baik dan bisa diterima. Tetapi sesungguhnya itu menyatakan bahwa mereka tidak menghargai serta tidak menghormati pengundang.

Ayat 21-22: Undangan yang kedua (orang-orang miskin, cacat, lumpuh). Penolakan terhadap undangan tersebut ternyata membuat tuan itu marah. Sebagai gantinya yang diundang adalah orang-orang yang miskin, yang cacat, lumpuh, buta, dsb. Mereka ini semula tidak termasuk dalam hitungan. Kelompok orang seperti ini tentunya sangat senang diundang makan yang enak. Karena itu mereka tidak menolak. Tetapi tempat masih banyak yang kosong.

Para pelayan/pesuruh kembali melapor pada tuannya dan menjelaskan tentang sikap dan penolakan orang-orang yang diundang tadi untuk datang memenuhi undangan tuannya (ayat 21). Laporan itu kemudian diikuti oleh perintah tuannya agar mengundang semua orang yang ada di jalan-jalan, di lorong-lorong yaitu mereka yang miskin dan yang cacat fisik (lumpuh, buta). Keadaan orang-orang itu sangat berbeda dengan kondisi undangan pertama yang menolak.

Ayat 23 : Undangan yang ketiga atau yang terakhir. Karena tempat yang tersedia masih belum terisi penuh, maka tuan itu memeritahkan kepada hambanya untuk memanggil secara paksa orangorang yang dijumpai di berbagai tempat. Kelompok ini tidak bisa diklasifikasikan sebagai siapa. Tetapi yang jelas, tidak ada kesempatan bagi mereka untuk menolak undangan itu (karena dipaksa) Para pelayan telah melaksanakan tugas memanggil orang-orang yang dimaksud tuannya. Meskipun orang-orang seperti yang dikatakan oleh tuannya tadi 
dipanggil semua, tetapi ternyata tempat yang tersedia masih banyak yang kosong. Akhirnya tuan itu meminta para pesuruhnya ke 'segala' tempat dan 'memaksa agar-orang yang dijumpai menghadiri perjamuan yang sudah siap itu.

Ayat 24 : Tanggapan akhir penyelenggara perjamuan. Ini merupakan pengungkapan perasaan tuan rumah terhadap pesta yang diselenggarakan. Komentar terhadap orang yang menolak undangan itu tentu bernada kecewa. Menarik sekali ucapannya: "Tidak ada seorang pun dari orang-orang yang telah diundang itu akan masuk jamuanKu". Yang dimaksud undangan di sini tentulah orang-orang yang menolak tadi.

\section{Tingkatan-tingkatan intensitas undangan}

\begin{tabular}{|c|c|c|}
\hline $\begin{array}{c}\text { Orang yang } \\
\text { diundang }\end{array}$ & $\begin{array}{c}\text { Cara } \\
\text { mengundang }\end{array}$ & $\begin{array}{l}\text { Respons } \\
\text { undangan }\end{array}$ \\
\hline $\begin{array}{l}\text { Orang-orang } \\
\text { terhormat }\end{array}$ & $\begin{array}{l}\text { Dengan cara } \\
\text { terhormat }\end{array}$ & $\begin{array}{l}\text { Menolak dengan } \\
\text { berbagai macam } \\
\text { dalih }\end{array}$ \\
\hline $\begin{array}{l}\text { Orang-orang yang } \\
\text { miskin, cacat, buta, } \\
\text { lumpuh dsb. }\end{array}$ & Dengan ajakan biasa & $\begin{array}{l}\text { Mengikuti undangan } \\
\text { itu }\end{array}$ \\
\hline $\begin{array}{l}\text { Semua orang yang } \\
\text { ditemui di mana } \\
\text { saja }\end{array}$ & Dengan cara paksa & $\begin{array}{l}\text { Tidak bisa menolak } \\
\text { (tidak dijelaskan } \\
\text { dalam perumpamaan } \\
\text { ini) }\end{array}$ \\
\hline
\end{tabular}

\section{Catatan interpretasi}

Ayat 16. Bahasa Yunani $\delta \varepsilon \imath \pi v o v$ bisa diterjemahkan sebagai pesta atau perjamuan besar (great banquet; great supper) yang menyatakan keadaan pesta yang mewah. Berarti pengundang adalah orang yang benar-benar kaya.

Ayat 17. Undangan dilakukan oleh seorang pelayan. Berbeda dengan Matius yang menuliskan banyak pelayan yang diutus untuk mengundang 
para tamu. Mungkin ini men unjuk pada diri Yesus sendiri, sedangkan pada Matius termasuk para nabi. ${ }^{11}$

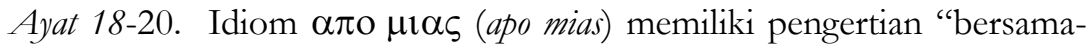
sama" atau "satu pikiran". Jadi orang-orang yang diundang itu memiliki kesepakan untukmmenolak undangan yang dimaksud. Kawin $\varepsilon \gamma \eta \mu \alpha$ (egema) kata kerjanya berbentuk aorist. Ini jelas, bahwa orang itu sengaja memakai kawin itu sebagai alasan untuk menolak undangan.

Ayat 21. Tuan itu sangat marah dengan sikap orang-orang yang menolak. Istilah $\tau \alpha u \tau \alpha$ (tauta) menunjukkan kumpulan reaksi kemarahan terhadap tiga respons mereka. Akhirnya, sebagai ganti terhadap undangan yang terhormat tadi, tuan itu mengalihkan undangannya kepada setiap orang (miskin, cacat, lumpuh dsb.). Berarti orang yang tadinya tidak diperhitungkan malah mendapatkan kehormatan.

Ayat 22. Meskipun orang-orang dalam klasifikasi di atas sudah diundang, tetapi toh ruangan masih banyak yang kosong. Padahal persediaan makanan dan ruang pasti sangat banyak.

Ayat 23. Karena itu undangan diberikan kepada "siapa saja" yang ditemui di seluruh pelosok kota untuk memenuhi ruangan tersebut. Tidak dicatat apakah akhirnya ruangan itu penuh atau tidak. Yang jelas undangan itu semakin terbuka untuk semua orang.

Ayat 24. Konklusi. Orang yang sebenarnya diundang secara terhormat justru akhirnya akan tidak kebagian dalkam kenikmatan pesta. Di sini nampak kekecewaan tuan rumah tadi.

\section{KEBENARAN YANG DINYATAKAN}

${ }^{11}$ Bandingkan Bolland halaman 316 dengan Bock, halaman 1272. 
Tujuan perumpaan ini jelas memberikan pengajaran kepada para pendengar tentang kebenaran penghakiman/penghukuman Allah serta serta pengajaran tentang Kerajaan Allah itu sendiri. Pertanyaanpertanyaan yang segera muncul barangkali:

1. Siapakah tuan yang menyelenggarakan perjamuan itu?

2. Siapakah hamba/pelayan yang disuruh memanggil para tamu?

3. Siapakah tamu-tamu tersebut?

4. Apakah sebenarnya perjamuan besar yang diadakan itu?

5. Lalu, siapa atau apa yang paling diutamakan dalam perumpamaan ini?

Scott mengatakan bahwa perjamuan besar (feasting) hampir selalu menunjukkan tentang kemenangan Allah terhadap para musuh-Nya ${ }^{12}$ (bandingkan ini dengan Mazmur 23:5 $\rightarrow$ Engkau menyediakan hidanganku di hadapan para lawanku).

Bagaimana pun, perumpamaan ini memiliki arti yang sangat mendalam tentang sejarah keselamatan, yang berkaitan dengan Kingdom of God dan Judgment. Nampak sekali tokoh- tokoh yang dimunculkan disini adalah tokoh-tokoh utama dalam Kerajaan Allah. Sehingga tentunya juga tidak terlalu sulit untuk memahami bahwa :

Pertama,Tuan itu adalah Allah Bapa yang berdaulat dengan panggilan dan anugerah-Nya. Dia bisa menentukan akan memilih siapa yang dikehendaki. Tetapi Allah kita juga diberikan kebebasan sikap. Menolak atau menerima. Tentunya dengan segala risiko atau konsekuensi yang harus ditanggungnya.

Kedua, Pelayan yang disuruh mengundang para tamu itu adalah Anak-Nya sendiri (karena dalam bentuk tunggal, seorang hamba),

12 Bernard Brandon Scott, ibid, halaman 169. 
berbeda dengan Matius 22:1-10 yang dinyatakan dalam bentuk jamak, pelayan-pelayan. Oleh karena itu kebanyakan sarjana atau penafsir berani mengatakan bahwa ini jelas menyatakan atau mewakili Yesus Kristus sendiri. ${ }^{13}$

Ketiga, Orang-orang yang diundang pertama tetapi menolak dengan berbagai alasan, hal ini bisa menunjuk kepada para ulama atau orangorang Yahudi, atau orang-orang yang seharusnya lebih dulu mendapat kesempatan memeroleh berkat, tetapi menolak anugerah yang ditawarkan melalui Yesus. ${ }^{14}$

Keempat, Orang-orang cacat, timpang, miskin dan orang-orang lainnya itu adalah orang-orang yang semula dianggap orang yang tidak layak memeroleh anugerah, berkat, terbuang, tetapi akhirnya justru mendapat kesempatan memeroleh anugerah yang tidak dibayangkan sebelumnya. Hal ini berkaitan dengan pemberian anugerah Allah terhadap orang-orang kafir. Lockyer mengatakan:

The first call represents salvation offered to the Jew, and his rejection of the Saviour. The second call to the poor, maimed, halt and blind, symbolyzes the Gentile sinners and harlots who warmly welcomed the King's Son and pressed eagerly into His Kingdom. The third call was to a yet lower class, tramps and souatters whose only home was the highways and hedges, who represent the wanderers of the outlying Gentile world, the world's "broken earthenware", upon whom woral compulsion has to be used. This is the constraint, equivalent to the love of Christ, which Paul brought to bear upon Men (II Corintian 5:14) 15

Kelima, Rumah tempat Perjamuan besar itu dilaksanakan bisa menyatakan tentang Kerajaan Surga. Undangan Allah masuk ke

13 R.A. Jaffray. Pewrumpamaan Jilid 2. (Bandung: Penerbit Kalam Hidup, 1974), 51.

14 B.J. Bolland, 316.

${ }^{15}$ Herbert Loycker, 278. 
perjamuan, juga menunjukkan bagaimana Allah itu selalu menyediakan segala sesuatu dengan sempurna. Segala jiwa yang lapar, haus dan dahaga seharusnya datang memenuhi undangan itu. Inilah anugerah Allah yang sangat besar, kita bisa datang, makan dengan tidak usah membayar. Ini mengingatkan juga terhadap kata-kata nabi Yesaya: "Ayo, hai semua orang yang haus, marilah dan minumlah air, dan hai orang yang tidak mempunyai uang, marilah! Terimalah gandum tanpa uang pembeli makanlah, juga anggur dan susu tanpa bayaran! “ (Yesaya 55:1).

Bolland menuturkan bahwa cerita ini adalah suatu perumpamaan yang mau menunjukkan tentang bagaimana Allah itu seharusnya bertindak. ${ }^{16}$ Memang, justru dalam hal mengutus Anak-Nya, Yesus Kristus ke dalam dunia ini menjadi jelaslah bahwa Allah memang bertindak dengan cara sedemikian itu. Khususnya dalam Injil Lukas sangat ditekankan bahwa "Anak Manusia itu datang untuk mencari dan menyelamatkan yang hilang” (Luk. 19:10).

\section{KESIMPULAN}

Meskipun kita berusaha untuk tidak menafsirkan bagian ini secara alegoris, namun disini nampak dengan jelas apa dan siapa yang dimaksudkan oleh penginjil Lukas melalui perumpamaan ini. Kaitan langsung denmgan Kerajaan Allah, Allah Bapa, Yesus Kristus, Orangorang Yahudi (khususnya para pemimpinnya), orang-orang kafir dan sebaginya. Waktu perjamuan yang "sudah tersedia, segala sesuatu sudah siap" juga menyatakan "waktu" yang sudah tidak bisa ditawar-tawar atau ditunggu-tunggu lagi.

Ajakan harus ditanggapi. Penolakan harus disertai kesiapan menanggung risiko. Anugerah yang tidak bisa ditolak (pemanggilan paksa, ayat 23), tidak memebrikan tempat bagi yang menolak dsb., merupakan pokok-pokok penting dari perumpamaan ini.

16 B.J. Bolland, 317. 
HADI P. SAHARDJO, menyelesaikan pendidikan Psikologi Pendidikan dan Bimbingan Konseling (Drs) dari IKIP (sekarang Universitas) Negeri Malang, dan menempuh pendidikan teologi dari SAAT, Malang (B.Th., S.Th., M.A., M.Div.); dan dari International Theological Seminary, ITS, Los Angeles, USA, (Th.M.) serta ABGTS/STBI Semarang (D.Th.). Sekarang sebagai dosen tetap di STT SAPPI Cianjur. 